\title{
Morbidly Obese Patients Exhibit Increased CYP2E1-Mediated Oxidation of Acetaminophen
}

\author{
Anne van Rongen ${ }^{1,2}$ - Pyry A. J. Välitalo ${ }^{2}$ - Mariska Y. M. Peeters ${ }^{1}$. \\ Djamila Boerma $^{3}$ - Fokko W. Huisman ${ }^{4}$ Bert van Ramshorst ${ }^{3}$ - Eric P. A. van Dongen ${ }^{5}$. \\ Johannes N. van den Anker ${ }^{6,7,8}$ - Catherijne A. J. Knibbe ${ }^{1,2}$
}

Published online: 27 January 2016

(c) The Author(s) 2016. This article is published with open access at Springerlink.com

\begin{abstract}
Introduction Acetaminophen (paracetamol) is mainly metabolized via glucuronidation and sulphation, while the minor pathway through cytochrome P450 (CYP) 2E1 is held responsible for hepatotoxicity. In obese patients, CYP2E1 activity is reported to be induced, thereby potentially worsening the safety profile of acetaminophen. The aim of this study was to determine the pharmacokinetics of acetaminophen and its metabolites (glucuronide, sulphate, cysteine and mercapturate) in morbidly obese and non-obese patients.

Methods Twenty morbidly obese patients (with a median total body weight [TBW] of $140.1 \mathrm{~kg}$ [range $106-193.1 \mathrm{~kg}]$ and body mass index [BMI] of $45.1 \mathrm{~kg} / \mathrm{m}^{2}$ $\left[40-55.2 \mathrm{~kg} / \mathrm{m}^{2}\right]$ ) and eight non-obese patients (with a TBW of $69.4 \mathrm{~kg}$ [53.4-91.7] and BMI of $21.8 \mathrm{~kg} / \mathrm{m}^{2}$ [19.4-27.4]) received $2 \mathrm{~g}$ of intravenous acetaminophen. Fifteen blood samples were collected per patient. Population pharmacokinetic modelling was performed using NONMEM.
\end{abstract}

Electronic supplementary material The online version of this article (doi:10.1007/s40262-015-0357-0) contains supplementary material, which is available to authorized users.

Catherijne A. J. Knibbe

c.knibbe@antoniusziekenhuis.nl

1 Department of Clinical Pharmacy, St. Antonius Hospital, Koekoekslaan 1, 3435 CM Nieuwegein, The Netherlands

2 Division of Pharmacology, Leiden Academic Center for Drug Research, Leiden University, Leiden, The Netherlands

3 Department of Surgery, St. Antonius Hospital, Nieuwegein, The Netherlands

4 Department of Oral and Maxillofacial Surgery, St. Antonius Hospital, Nieuwegein, The Netherlands
Results In morbidly obese patients, the median area under the plasma concentration-time curve from 0 to $8 \mathrm{~h}$ $\left(\mathrm{AUC}_{0-8 \mathrm{~h}}\right)$ of acetaminophen was significantly smaller $(P=0.009)$, while the $\mathrm{AUC}_{0-8 \mathrm{~h}}$ ratios of the glucuronide, sulphate and cysteine metabolites to acetaminophen were significantly higher $(P=0.043,0.004$ and 0.010 , respectively). In the model, acetaminophen CYP2E1-mediated clearance (cysteine and mercapturate) increased with lean body weight $[\mathrm{LBW}]$ (population mean [relative standard error] $0.0185 \mathrm{~L} / \mathrm{min}$ [15\%], $P<0.01$ ). Moreover, accelerated formation of the cysteine and mercapturate metabolites was found with increasing LBW $(P<0.001)$. Glucuronidation clearance $(0.219 \mathrm{~L} / \mathrm{min}[5 \%])$ and sulphation clearance $(0.0646 \mathrm{~L} / \mathrm{min}$ [6 \%]) also increased with LBW $(P<0.001)$.

Conclusion Obesity leads to lower acetaminophen concentrations and earlier and higher peak concentrations of acetaminophen cysteine and mercapturate. While a higher dose may be anticipated to achieve adequate acetaminophen concentrations, the increased CYP2E1-mediated pathway may preclude this dose adjustment.

Department of Anesthesiology and Intensive Care, St. Antonius Hospital, Nieuwegein, The Netherlands

6 Division of Clinical Pharmacology, Children's National Medical Center, Washington DC, USA

7 Department of Pediatric Pharmacology, University Children's Hospital, Basel, Switzerland

8 Intensive Care and Department of Pediatric Surgery, Erasmus Medical Center-Sophia Children's Hospital, Rotterdam, The Netherlands 


\section{Key Points}

Cytochrome P450 (CYP) 2E1-mediated clearance of acetaminophen to acetaminophen cysteine and mercapturate increases with lean body weight, while the formation of these cysteine and mercapturate metabolites is also accelerated.

Besides increased CYP2E1-mediated clearance, glucuronidation and sulphation clearance are also increased in morbidly obese patients, which results in lower exposure to acetaminophen.

While a higher dose of acetaminophen may be anticipated to achieve adequate acetaminophen concentrations in morbidly obese patients, the increased CYP2E1-mediated pathway may preclude this dose adjustment.

\section{Introduction}

Worldwide, the prevalence rates of obesity (body mass index $[\mathrm{BMI}] \geq 30 \mathrm{~kg} / \mathrm{m}^{2}$ ) are increasing. In the USA, roughly a third of men $(31.6 \%)$ and women $(33.9 \%)$ were obese in 2013 [1]. Also, in other parts of the world-i.e. the Middle East (Qatar, Kuwait and Saudi Arabia), Africa (Libya, South Africa and Egypt) and Oceania (Tonga, Samoa and Kiribati) - high prevalence rates of obesity (30-69.1\%) have been reported [1].

Acetaminophen (paracetamol) is a frequently used analgesic in the peri- and postoperative setting. After bariatric surgery or weight loss surgery, scheduled intravenous acetaminophen has been reported to significantly reduce narcotic analgesic requirements during the first $24-\mathrm{h}$ postoperative period [2]. Acetaminophen is extensively metabolized by different metabolic pathways in the liver. The main pathways are glucuronidation (around $55 \%$, by uridine diphosphate [UDP] glucuronosyltransferases [UGTs]) and sulphation (around $30 \%$, by sulphotransferase) [3-5], while only $2-5 \%$ of acetaminophen is excreted unchanged $[3,5]$. Approximately 5-10\% of acetaminophen is metabolized by cytochrome $\mathrm{P} 450$ (CYP), primarily by the CYP2E1 enzyme [6-8], to the toxic metabolite $N$-acetyl-p-benzoquinone imine (NAPQI) [3-5, 9]. At therapeutic doses, NAPQI is immediately inactivated by conjugation with glutathione to a neutral metabolite and is excreted as cysteine and mercapturate metabolites in urine [10]. Hepatotoxicity occurs when glutathione stores are depleted (e.g. after an acetaminophen overdose or chronic alcohol abuse), resulting in conjugation of NAPQI to cytosolic and mitochondrial proteins, leading to hepatocellular necrosis $[10,11]$. Intentional acetaminophen overdose is the most common cause of acute liver failure in the USA [12].

In obese subjects, both the volume of distribution and the total clearance of acetaminophen are reported to be increased in comparison with non-obese subjects [13]. As such, obese patients may need higher loading and maintenance doses of acetaminophen. However, since one of the metabolic pathways of acetaminophen (i.e. the CYP2E1mediated pathway) is involved in hepatotoxicity, it is important to explore the separate contributions of the different metabolic pathways to the increased total clearance of acetaminophen. To date, the contributions of the different metabolic pathways of acetaminophen have not been investigated in morbidly obese patients. In obese patients, glucuronidation capacity and CYP2E1-mediated clearance or CYP2E1 expression are expected to be induced [14-19], while the influence of obesity on sulphation is unclear [2023]. It is anticipated that non-alcoholic fatty liver disease (NAFLD), which is associated with obesity, is the underlying cause of increased CYP2E1 expression in obese patients [24]. The aim of this study was to determine the pharmacokinetics of acetaminophen, with a specific emphasis on the contributions of the metabolites (glucuronide, sulphate, cysteine and mercapturate), in morbidly obese patients in comparison with non-obese patients.

\section{Methods}

\subsection{Patients}

Morbidly obese adult patients (BMI $>40 \mathrm{~kg} / \mathrm{m}^{2}$ ) undergoing bariatric surgery (laparoscopic gastric bypass and sleeve surgery) and non-obese adult patients undergoing oral and maxillofacial surgery were considered for participation in the study. Patients were excluded if they were pregnant or breastfeeding, were smokers, suffered from renal insufficiency (glomerular filtration rate [GFR; Modification of Diet in Renal Disease (MDRD) ] $<60 \mathrm{~mL} / \mathrm{min} \cdot 1.73 \mathrm{~m}^{2}$ ), or had a liver disease identified by liver function tests (aspartate aminotransferase [AST] or alanine aminotransferase [ALT] $>3$ times the upper limit of normal values), type 2 diabetes mellitus, Gilbert-Meulengracht syndrome or prior exposure to acetaminophen within a 24-h period. In addition, patients with chronic alcohol intake, patients who had used alcohol within the previous $72 \mathrm{~h}$ and patients treated with drugs known to affect CYP2E1 (disulfiram and isoniazide) or UGT (such as oestradiol-containing contraceptives, certain antiepileptics and antiretroviral drugs) were excluded. Before participation, patients provided written informed consent. The study was approved by the local human research and ethics committee of St. Antonius Hospital (VCMO, NL39958.100.12) and was conducted in 
accordance with the principles of the Declaration of Helsinki and the Medical Research Involving Human Subjects Act (WMO) of the Netherlands.

\subsection{Study Design}

In this prospective observational study (ClinicalTrials.gov study ID NCT01764555; EudraCT number 2012-00095632) 20 morbidly obese and 8 non-obese patients were studied on the day of surgery. All patients received a $2 \mathrm{~g}$ intravenous dose of acetaminophen (two flacons of Fresenius Kabi $10 \mathrm{mg} / \mathrm{mL}, 100 \mathrm{~mL}$ administered over $20 \mathrm{~min}$ with a volumetric pump) before induction of anaesthesia. Blood samples were collected at $T=0,2.5,7.5,15,30$ and $45 \mathrm{~min}$; and 1, 1.5, 2, 2.5, 3, 4, 5, 6 and $8 \mathrm{~h}$ after the end of the $2 \mathrm{~g}$ infusion. After $8 \mathrm{~h}$ of blood sampling, the standard postoperative pain protocol was initiated (i.e. $1 \mathrm{~g}$ of intravenous acetaminophen every $6 \mathrm{~h}$ ). One last blood sample was taken at $24 \mathrm{~h}$ after the end of the $2 \mathrm{~g}$ acetaminophen infusion and other acetaminophen doses given according to the standard protocol. Blood samples were collected in lithium-heparin tubes and centrifuged at $2000 \mathrm{~g}$ for $10 \mathrm{~min}$ at $4{ }^{\circ} \mathrm{C}$, and the plasma was stored at $80{ }^{\circ} \mathrm{C}$ until analysis.

Blood samples for liver function tests (AST, ALT, prothrombin time [PT], $\gamma$-glutamyltranspeptidase $[\gamma-\mathrm{GT}]$ and bilirubin) were collected before acetaminophen administration and at $T=24 \mathrm{~h}$. Blood samples for insulin resistance (homeostatic model assessment of insulin resistance [HOMA-IR], (fasting insulin levels and glucose levels)), lipid levels (free fatty acid, triglyceride and cholesterol levels) and C-reactive protein (CRP) levels were collected before acetaminophen administration. HOMA-IR was calculated as (glucose $\times$ insulin)/22.5.

\subsection{Drug Assays}

Acetaminophen, acetaminophen glucuronide, acetaminophen sulphate, acetaminophen glutathione, acetaminophen cysteine and acetaminophen mercapturate were measured using high-performance liquid chromatography-electrospray ionization-tandem mass spectrometry (HPLC-ESI-MS/MS) at the Center for Human Toxicology, University of Utah (Salt Lake City, UT, USA) [25]. The assays were linear over $0.05-50 \mu \mathrm{g} / \mathrm{mL}$ for acetaminophen, acetaminophen glucuronide and acetaminophen sulphate, and over $0.025-5.0 \mu \mathrm{g} / \mathrm{mL}, 0.01-5.0 \mu \mathrm{g} / \mathrm{mL}$ and $0.01-1.0 \mu \mathrm{g} / \mathrm{mL}$ for acetaminophen glutathione, acetaminophen cysteine and acetaminophen mercapturate, respectively, with the lower limits of the ranges representing the lower limits of quantification (LLOQs) of acetaminophen and its metabolites. Intraand inter-assay accuracies ranged from 80 to $112 \%$, and intraand inter-assay imprecision did not exceed $15 \%$.

\subsection{Statistical Analysis}

The area under the plasma concentration-time curve (AUC) from 0 to $8 \mathrm{~h}\left(\mathrm{AUC}_{0-8 \mathrm{~h}}\right)$ values for acetaminophen, acetaminophen glucuronide, acetaminophen sulphate, acetaminophen cysteine and acetaminophen mercapturate after dosing of acetaminophen were calculated for each patient separately, using the linear trapezoidal rule in $\mathrm{R}$ software (version 3.0.1) [26]. One non-obese patient was excluded from $\mathrm{AUC}_{0-8 \mathrm{~h}}$ calculation, since this patient had acetaminophen and metabolite concentrations measured only until $6 \mathrm{~h}$, instead of $8 \mathrm{~h}$, post-dose. The $\mathrm{AUC}_{0-8 \mathrm{~h}}$ ratio of each metabolite to acetaminophen ( $\mathrm{AUC}_{0-8 \mathrm{~h} \text { metab }}$ $\mathrm{AUC}_{0-8 \mathrm{~h} \text { apap }}$ ) was calculated for all metabolites in all individuals. The Mann-Whitney test was applied to test statistical differences in the median $\mathrm{AUC}_{0-8 \mathrm{~h}}$ values for acetaminophen, the metabolite-to-acetaminophen ratios and demographic variables between morbidly obese and non-obese patients. The Wilcoxon rank test was used to test statistical differences between liver function samples before acetaminophen administration $(T=0)$ and $24 \mathrm{~h}$ after administration $(T=24)$. These statistical analyses were performed using IBM SPSS version 22 software.

\subsection{Population Pharmacokinetic Analysis and Internal Model Validation}

Acetaminophen and metabolite data were analysed using non-linear mixed effects modelling with NONMEM version 7.2 software (Icon Development Solutions, Hanover, MD, USA) [27]. Pirana version 2.9.1 [28], R version 3.0.1 [26], Xpose version 4.5.0 [28] and Psn version 3.6.2 [28] software were used to evaluate and visualize the data. Concentrations were expressed in micromoles per litre, using the molecular weights of acetaminophen, acetaminophen glucuronide, acetaminophen sulphate, acetaminophen cysteine and acetaminophen mercapturate (151.16, 327.29, 231.23, 270.30 and $312.24 \mathrm{~g} / \mathrm{mol}$, respectively), and the concentrations were logarithmically transformed. No glutathione concentrations could be measured in either of the patient groups $(<L L O Q)$. For acetaminophen, acetaminophen glucuronide, acetaminophen sulphate, acetaminophen cysteine and acetaminophen mercapturate, 1 sample $(0.25 \%), 0$ samples $(0 \%)$, 0 samples $(0 \%), 2$ samples $(0.49 \%)$ and 70 samples $(17.3 \%)$, respectively, were below the LLOQs and were removed from the analysis $[29,30]$. The first-order conditional estimation method was used for model development. Discrimination between different models was guided by the likelihood ratio test, by comparison of the objective function value $(\mathrm{OFV})$ [i.e. $-2 \log$ likelihood $(-2 \mathrm{LL})$ ] between nested models. A $P$ value of $<0.05$, representing a change in the OFV $[\triangle \mathrm{OFV}]$ of -3.84 for one degree of freedom, 
was considered statistically significant. In addition, goodness-of-fit plots for acetaminophen, acetaminophen glucuronide, acetaminophen sulphate, acetaminophen cysteine and acetaminophen mercapturate in morbidly obese and non-obese patients (observed versus individual-predicted concentrations, observed versus population-predicted concentrations, conditional weighted residuals [CWRES] versus time after dose, and CWRES versus populationpredicted concentrations) were used for diagnostic purposes. Furthermore, precision of parameter estimates, the correlation matrix and visual improvement in the individual plots were used to evaluate the model. Pharmacokinetic models incorporating one, two or three compartments for acetaminophen and one or two compartments for the metabolites were tested. To capture eventual delay in formation of acetaminophen metabolites, a varying number of transit compartments was tested. The mean transit time (MTT) was calculated from the transit compartment rate constant (Ktr) with $n / \mathrm{Ktr}$, where $n$ is the number of transit compartments. The CYP2E1 metabolites, i.e. acetaminophen cysteine and acetaminophen mercapturate, were modelled in one compartment [31]. The volume of distribution of acetaminophen sulphate ( $\left.V_{\text {sulphate }}\right)$ was assumed to be 5.66 L (5.66 FIX) [31], and the volume of distribution of acetaminophen cysteine and mercapturate $\left(V_{\text {cysteine and mer- }}\right.$ capturate) was assumed to be 15.6 L (15.6 FIX) [31] (Fig. 1). The unchanged acetaminophen clearance $\left(\mathrm{CL}_{\text {unchanged }}\right)$ was assumed to be $5 \%$ of the total clearance $\left(\mathrm{CL}_{\text {tot }}\right.$; calculated as $\left.\mathrm{CL}_{\text {tot }}=\mathrm{CL}_{\text {unchanged }}+\mathrm{CL}_{\text {gluc }}+\mathrm{CL}_{\text {sulph }}+\mathrm{CL}_{\mathrm{CYP} 2 \mathrm{E} 1}\right)$ of a $70 \mathrm{~kg}$ individual (Fig. 1), where $\mathrm{CL}_{\text {gluc }}$ is glucuronidation clearance, $\mathrm{CL}_{\text {sulph }}$ is sulphation clearance and $\mathrm{CL}_{\mathrm{CYP} 2 \mathrm{E} 1}$ is CYP2E1-mediated clearance. Inter-individual variability (IIV) was assumed to follow a log-normal distribution. Residual variability was tested using proportional, additive or combined proportional and additive error models for acetaminophen and the metabolites. For internal model evaluation, a bootstrap resampling method using 1000 replicates and visual predictive checks (VPCs) stratified for acetaminophen, acetaminophen glucuronide, acetaminophen sulphate, and acetaminophen cysteine and mercapturate, using 1000 simulated data sets of individuals from the original data set, were used.

\subsection{Covariate Model}

The tested covariates were total body weight (TBW), BMI, lean body weight (LBW; according to the equation of Janmahasatian et al. [32]), age and sex. Covariates were plotted independently against the eta $(\eta)$ estimates of the pharmacokinetic parameters to visualize potential relations. Continuous covariates were tested using linear and power equations (Eqs. 1, 2):

$$
\begin{aligned}
& P_{\mathrm{i}}=P_{\mathrm{p}}\left(1+Y\left(\mathrm{COV}-\mathrm{COV}_{\text {median }}\right)\right) \\
& P_{\mathrm{i}}=P_{\mathrm{p}}\left(\mathrm{COV} / \mathrm{COV}_{\text {median }}\right)^{X}
\end{aligned}
$$

where $P_{\mathrm{i}}$ and $P_{\mathrm{p}}$ represent the individual and population parameter estimates, respectively, $\mathrm{COV}$ represents the covariate, $\mathrm{COV}_{\text {median }}$ represents the median value of the covariate for the population, $Y$ represents a correlation factor between the population pharmacokinetic parameter and the change in the covariate value for a linear function, and $X$ represents the exponent for a power function. The categorical covariate sex was examined by calculation of a separate parameter for each category of the covariate.

Potential covariates were entered into the model one at a time and statistically tested by the likelihood ratio test. In

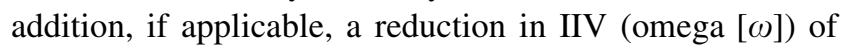

Fig. 1 Schematic illustration of the population pharmacokinetic model. $C L_{\text {unchanged }}$ unchanged clearance of acetaminophen, $C L_{\text {gluc }}$ glucuronidation clearance, $C L_{\text {sulp }}$ sulphation clearance, $C L_{C Y P 2 E 1}$ CYP2E1mediated clearance, $C L_{E}$ gluc glucuronide elimination clearance, $C L_{E}$ sulph sulphate elimination clearance, $C L_{E}$ cys\&mercap cysteine \& mercapturate elimination clearance, $\operatorname{Ktr}_{\text {CYP2E1 }}$ CYP2E1 transit compartment rate constant, Ktr $r_{\text {gluc }}$ glucuronide transit compartment rate constant, $Q$ inter-compartmental clearance of acetaminophen sulphate between the central and peripheral compartment, $V$ volume of distribution

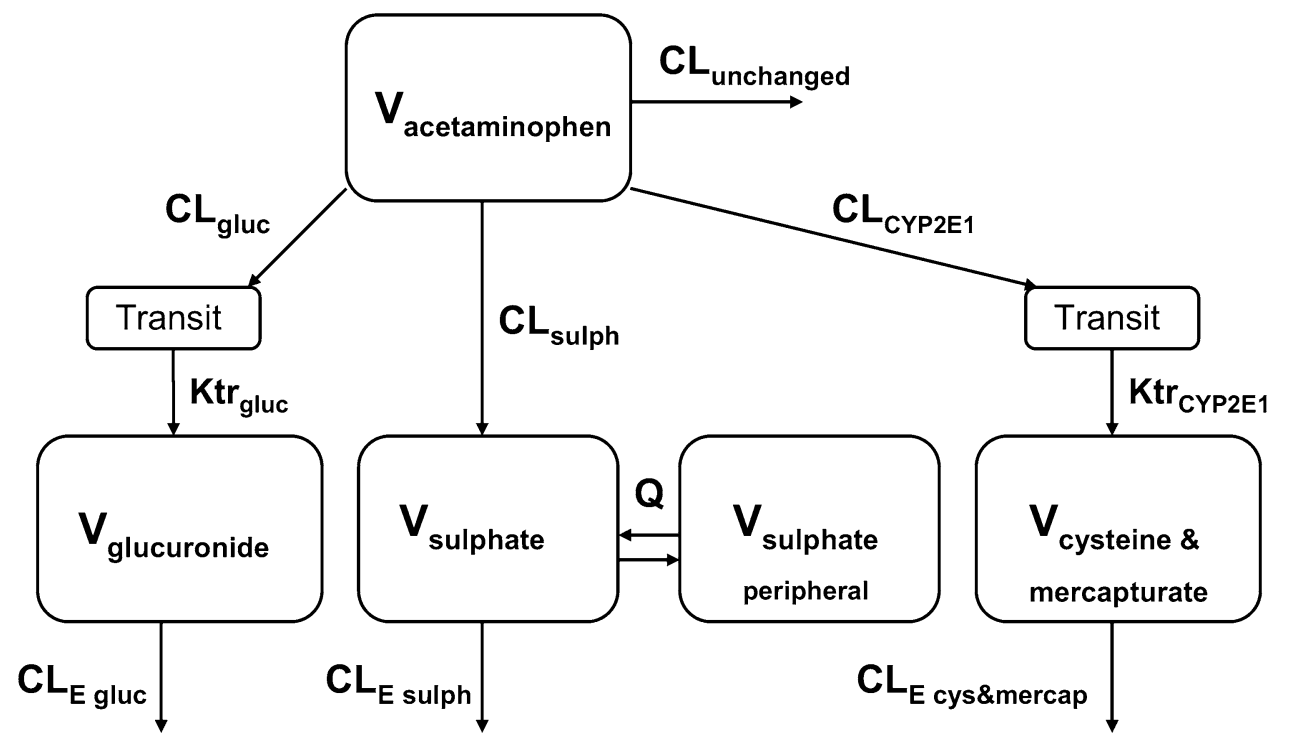


the parameter was evaluated upon inclusion of the covariate on the parameter. Further, trends in the random effects of the parameter versus the covariate involved were observed. When more than one significant covariate was identified, the covariate-adjusted model with the largest decrease in the OFV was chosen as a basis to sequentially explore the influence of additional covariates with the use of the same criteria. Finally, after forward inclusion $(P<0.01)$, a backward exclusion procedure was applied to justify the inclusion of a covariate $(P<0.001)$. The choice of the final covariate model was further evaluated as discussed in the 'Population Pharmacokinetic Analysis and Internal Model Validation' section.

\subsection{Simulations}

To examine the effect of obesity on acetaminophen and metabolite concentrations, the final population pharmacokinetic model was used to simulate concentration-time curves upon a $2 \mathrm{~g}$ intravenous infusion (administration time $20 \mathrm{~min}$ ) in four typical patients from the data set, i.e. a non-obese patient weighing $60.1 \mathrm{~kg}$ (LBW $41.2 \mathrm{~kg}$ ) and three morbidly obese patients weighing 106, 134 and $193 \mathrm{~kg}$ (LBWs 51.3, 65.8 and $96.2 \mathrm{~kg}$, respectively). The
$134 \mathrm{~kg}$ patient represents a patient around the median body weight, and the 106 and $193 \mathrm{~kg}$ individuals represent the two extremes in the data set of the morbidly obese patients in the study population.

\section{Results}

\subsection{Patients and Data}

Twenty morbidly obese patients and eight non-obese patients participated in this study. Median numbers of 15 acetaminophen samples, 15 acetaminophen glucuronide samples, 15 acetaminophen sulphate samples, 15 acetaminophen cysteine samples and 12 acetaminophen mercapturate samples per patient were available for analysis. The patient characteristics are summarized in Table 1. Morbidly obese patients had significantly higher levels of $\gamma$-GT, triglycerides, glucose, insulin, HOMA-IR and CRP than non-obese patients before administration of acetaminophen. According to the standard postoperative pain protocol, morbidly obese and non-obese patients received (in addition to the $2 \mathrm{~g}$ intravenous acetaminophen study dose) median acetaminophen doses of $3 \mathrm{~g}(0-3 \mathrm{~g})$ and $2 \mathrm{~g}$
Table 1 Demographics of 20 morbidly obese patients and 8 non-obese patients

\begin{tabular}{|c|c|c|c|}
\hline Variable & $\begin{array}{l}\text { Morbidly obese } \\
\text { patients, } n=20\end{array}$ & $\begin{array}{l}\text { Non-obese } \\
\text { patients, } n=8\end{array}$ & $P$ value \\
\hline Female/male $[n]$ & $15 / 5$ & $4 / 4$ & - \\
\hline Age [years] & $41.5(22-58)$ & $41.0(18-50)$ & $>0.05$ \\
\hline Body weight [kg] & $140.1(106-193.1)$ & $69.6(53.4-91.7)$ & 0.001 \\
\hline LBW [kg] [32] & $65.4(50.5-96.2)$ & $50.9(36.0-67.5)$ & 0.049 \\
\hline BMI $\left[\mathrm{kg} / \mathrm{m}^{2}\right]$ & $45.1(40-55.2)$ & $21.8(19.4-27.4)$ & 0.001 \\
\hline Waist-to-hip ratio & $0.85(0.74-1.25)$ & $0.79(0.67-0.95)$ & $>0.05$ \\
\hline Surgery duration [min] & 59 (36-95) & $110.5(24-353)$ & 0.029 \\
\hline AST [U/L] & $26.0(14.0-40.0)$ & $22.0(18.0-28.0)$ & $>0.05$ \\
\hline ALT [U/L] & $30.5(12.0-58.0)$ & $19.5(7.0-33.0)$ & $>0.05$ \\
\hline$\gamma$-GT $[\mathrm{U} / \mathrm{L}]$ & $29.5(13.0-99.0)$ & $12.5(8.0-27.0)$ & 0.004 \\
\hline Bilirubin $[\mu \mathrm{mol} / \mathrm{L}]$ & $6.0(3.0-17.0)$ & $8.0(4.0-18.0)$ & $>0.05$ \\
\hline $\mathrm{PT}[\mathrm{s}]$ & $12.8(12.3-13.9)$ & $12.9(12.4-13.4)$ & $>0.05$ \\
\hline Albumin $[\mathrm{g} / \mathrm{L}]$ & $42.1(38.9-48.4)$ & $44.7(40.5-48.7)$ & $>0.05$ \\
\hline Creatinine $[\mu \mathrm{mol} / \mathrm{L}]$ & $62.5(48.0-100.0)$ & $75.5(52.0-96.0)$ & $>0.05$ \\
\hline Cholesterol $[\mathrm{mmol} / \mathrm{L}]$ & $4.9(3.2-6.5)$ & $5.2(3.4-6.6)$ & $>0.05$ \\
\hline Triglycerides [mmol/L] & $1.3(0.6-2.8)$ & $0.8(0.5-1.4)$ & 0.013 \\
\hline FFA [mmol/L] & $0.9(0.6-1.7)$ & $0.6(0.2-1.2)$ & $>0.05$ \\
\hline Glucose [mmol/L] & $5.4(4.6-7.5)$ & $5.0(4.6-5.5)$ & 0.023 \\
\hline Insulin [mU/L] & $23.0(8.3-66.5)$ & $8.9(2.6-19.8)$ & 0.001 \\
\hline HOMA-IR & $5.7(1.8-22.2)$ & $2.0(0.5-4.8)$ & 0.001 \\
\hline CRP [mg/L] & $6.5(3.0-21.0)$ & $<1(<1-5)$ & 0.001 \\
\hline
\end{tabular}

Values are expressed as median (range) unless specified otherwise $\gamma$-GT $\gamma$-glutamyltranspeptidase, $A L T$ alanine aminotransferase, $A S T$ aspartate aminotransferase, $B M I$ body mass index, CRP C-reactive protein, FFA free fatty acids, HOMA-IR homeostatic model assessment of insulin resistance, $L B W$ lean body weight, $P T$ prothrombin time 
(range 0-4 g), respectively, over $24 \mathrm{~h}(P>0.05)$, whereby three morbidly obese patients received acetaminophen as a rectal dose and one morbidly obese patient received it as an oral dose.

\subsection{Observed Acetaminophen and Metabolite Concentrations}

The median $\mathrm{AUC}_{0-8 \mathrm{~h}}$ value of acetaminophen was statistically lower in morbidly obese patients $(n=20)$ than in nonobese patients $(n=7)$ [37,795 versus $45,909 \mu \mathrm{mol} \cdot \mathrm{min} / \mathrm{L}$, $P=0.009]$. The median $\mathrm{AUC}_{0-8 \mathrm{~h}}$ ratios of acetaminophen glucuronide, acetaminophen sulphate and acetaminophen cysteine to acetaminophen were significantly higher in morbidly obese patients than in non-obese patients $(P=0.043,0.004$ and 0.010 , respectively) (Fig. 2a-c). There was no difference in the median $\mathrm{AUC}_{0-8 \mathrm{~h}}$ ratio of acetaminophen mercapturate to acetaminophen in morbidly obese patients compared with non-obese patients $(P>0.05)$ (Fig. 2d). The time to reach the maximum plasma concentration $\left(t_{\max }\right)$ of acetaminophen cysteine significantly decreased with TBW $(r=-0.52, P=0.005)$.

\subsection{Population Pharmacokinetic Model and Internal Model Evaluation}

A one-compartment model for acetaminophen, acetaminophen glucuronide and acetaminophen cysteine and mercapturate, and a two-compartment model for acetaminophen sulphate, with equalized volumes of distribution, best described the data (Fig. 1). The central and peripheral volume of acetaminophen sulphate were equalized, since these values were almost equal and the model resulted in a similar OFV $(P>0.05)$. A two-compartment model for acetaminophen glucuronide and acetaminophen cysteine and mercapturate improved the model fit but could not be accurately estimated; therefore, a onecompartment model for these metabolites was preferred to a two-compartment model. For the glucuronide metabolite and the cysteine and mercapturate metabolites, a transit compartment model ( $n=1$ transit compartment) was added $(P<0.001)$ (Fig. 1) to capture the delay in metabolite formation, which was observed in the CWRESversus-time plot of these metabolites. Inclusion of more transit compartments did not improve the model fit for the glucuronide metabolite and the cysteine and mercapturate metabolites $(P>0.05)$. Residual variability was best described by four proportional error models, i.e. for the acetaminophen, acetaminophen glucuronide, acetaminophen sulphate, and acetaminophen cysteine and mercapturate concentrations. Table 2 shows the parameter estimates of the base model without covariates.

The systematic covariate analysis identified a significant influence of LBW or TBW on seven different parameters. The first covariate was LBW for CYP2E1 transit compartment rate constant $\left(\mathrm{Ktr}_{\mathrm{CYP} 2 \mathrm{E} 1}\right)$, which was found to increase with LBW in a non-linear manner $(P<0.001$, $\triangle \mathrm{OFV}-38$ ), implying a decrease in the mean transit time (MTT) of acetaminophen cysteine and mercapturate in obese individuals (MTT $=1 / \mathrm{Ktr}$ ). Then LBW was
Fig. 2 Area under the plasma concentration-time curve from 0 to $8 \mathrm{~h}\left(\mathrm{AUC}_{0-8 \mathrm{~h}}\right)$ metaboliteto-acetaminophen ratios of a acetaminophen glucuronide, b acetaminophen sulphate, c acetaminophen cysteine and d acetaminophen mercapturate in non-obese patients $(n=7)$ versus morbidly obese patients $(n=20)$ after a $2 \mathrm{~g}$ intravenous acetaminophen dose. $* P<0.05$ (Mann-Whitney test) a

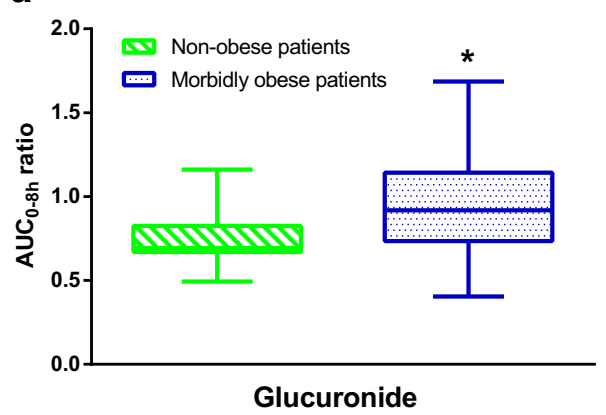

C

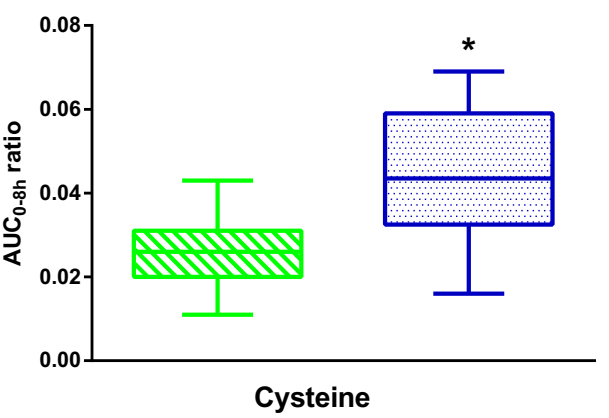

b

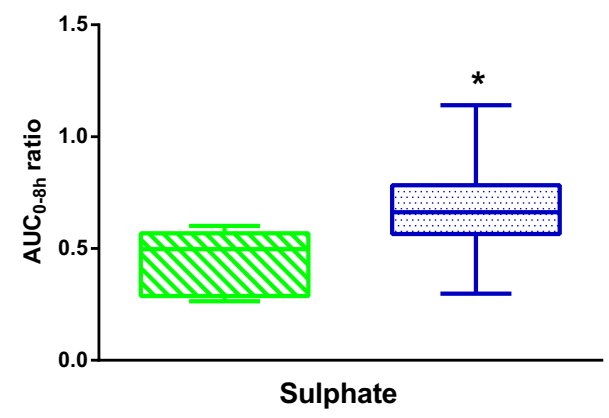

d

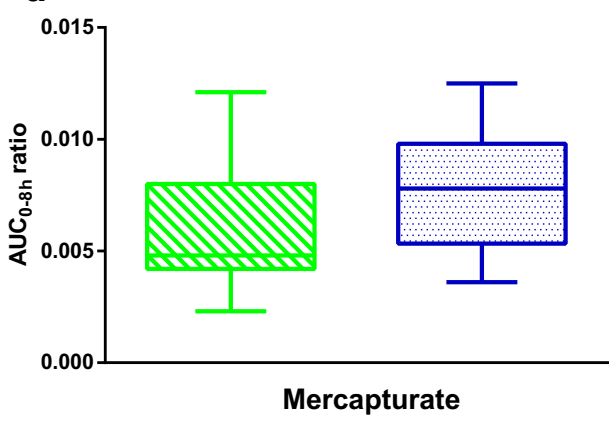


Table 2 Population pharmacokinetic parameters of the base and final pharmacokinetic models for acetaminophen in 20 morbidly obese patients and 8 non-obese patients, and results from bootstrap analysis of the final model (996/1000 resamples successful)

\begin{tabular}{|c|c|c|c|}
\hline Parameter & Base model (RSE \%) & Final model (RSE \%) & $\begin{array}{l}\text { Bootstrap } \\
\text { (95\% confidence interval) }\end{array}$ \\
\hline$V_{\text {acetaminophen }}[\mathrm{L}]$ & $64.4(5.3)$ & - & \\
\hline \multicolumn{4}{|l|}{$V_{\text {acetaminophen }}=V_{65.2 \mathrm{~kg}} \times[\mathrm{LBW} / 65.2]^{S}$} \\
\hline$V_{65.2 \mathrm{~kg}}$ & - & $67.2(2.8)$ & $67.3(64.1-70.9)$ \\
\hline$S$ & - & $0.90(17.4)$ & $0.90(0.59-1.22)$ \\
\hline $\mathrm{CL}_{\text {gluc }}[\mathrm{L} / \mathrm{min}]$ & $0.209(7.5)$ & - & \\
\hline \multicolumn{4}{|l|}{$\mathrm{CL}_{\text {gluc }}=\mathrm{CL}_{\text {gluc }, 65.2 \mathrm{~kg}} \times[\mathrm{LBW} / 65.2]^{T}$} \\
\hline $\mathrm{CL}_{\text {gluc, } 65.2 \mathrm{~kg}}$ & - & $0.224(5)$ & $0.223(0.202-0.246)$ \\
\hline$T$ & - & $1.33(17)$ & $1.34(0.85-1.75)$ \\
\hline $\mathrm{CL}_{\text {sulph }}[\mathrm{L} / \mathrm{min}]$ & $0.062(7)$ & - & \\
\hline \multicolumn{4}{|l|}{$\mathrm{CL}_{\text {sulph }}=\mathrm{CL}_{\text {sulph,65.2 } \mathrm{kg}} \times[\mathrm{LBW} / 65.2]^{U}$} \\
\hline $\mathrm{CL}_{\text {sulph,65.2 } \mathrm{kg}}$ & - & $0.065(6)$ & $0.065(0.057-0.073)$ \\
\hline$U$ & - & $0.92(19.9)$ & $0.92(0.55-1.34)$ \\
\hline $\mathrm{CL}_{\mathrm{CYP} 2 \mathrm{E} 1}[\mathrm{~L} / \mathrm{min}]$ & $0.018(14.8)$ & - & \\
\hline \multicolumn{4}{|c|}{$\mathrm{CL}_{\mathrm{CYP} 2 \mathrm{E} 1}=\mathrm{CL}_{\mathrm{CYP} 2 \mathrm{E} 1,65.2 \mathrm{~kg}} \times[\mathrm{LBW} / 65.2]^{W}$} \\
\hline $\mathrm{CL}_{\mathrm{CYP} 2 \mathrm{E} 1,65.2 \mathrm{~kg}}$ & - & $0.021(14.6)$ & $0.021(0.015-0.026)$ \\
\hline$W$ & - & $0.67(27.4)$ & $0.71(0.21-1.38)$ \\
\hline$V_{\text {glucuronide }}[\mathrm{L}]$ & $29.7(5.6)$ & - & \\
\hline \multicolumn{4}{|l|}{$V_{\text {glucuronide }}=V_{130.9 \mathrm{~kg}} \times[\mathrm{TBW} / 130.9]^{X}$} \\
\hline$V_{130.9 \mathrm{~kg}}$ & - & $32.3(4.1)$ & $32.4(29.7-34.9)$ \\
\hline$X$ & - & $0.55(23.3)$ & $0.56(0.27-0.83)$ \\
\hline$V_{\text {sulphate,central }}=V_{\text {sulphate,peripheral }}[\mathrm{L}]$ & 5.66 FIX & 5.66 FIX & 5.66 FIX \\
\hline$Q[\mathrm{~L} / \mathrm{min}]$ & $0.346(14.2)$ & $0.339(19.6)$ & $0.338(0.245-0.511)$ \\
\hline$V_{\text {cysteine and mercapturate }}[\mathrm{L}]$ & 15.6 FIX & 15.6 FIX & 15.6 FIX \\
\hline $\mathrm{Ktr}_{\mathrm{CYP} 2 \mathrm{E} 1}\left[\mathrm{~min}^{-1}\right]$ & $0.0063(11.7)^{\mathrm{a}}$ & - & \\
\hline \multicolumn{4}{|l|}{$\mathrm{Ktr}_{\mathrm{CYP} 2 \mathrm{E} 1}=\mathrm{Ktr}_{65.2 \mathrm{~kg}} \times[\mathrm{LBW} / 65.2]^{Y}$} \\
\hline $\mathrm{Ktr}_{65.2 \mathrm{~kg}}$ & - & $0.0057(12.2)^{\mathrm{b}}$ & $0.0058(0.0047-0.0079)$ \\
\hline$Y$ & - & $1.1(33)$ & $1.12(0.19-1.79)$ \\
\hline $\operatorname{Ktr}_{\text {gluc }}\left[\min ^{-1}\right]$ & $0.094(11)$ & $0.095(11.5)^{\mathrm{c}}$ & $0.095(0.076-0.121)$ \\
\hline $\mathrm{CL}_{\mathrm{E} \text { gluc }}[\mathrm{L} / \mathrm{min}]$ & $0.211(6.9)$ & - & \\
\hline \multicolumn{4}{|l|}{$\mathrm{CL}_{\mathrm{E} \text { gluc }}=\mathrm{CL}_{\mathrm{E} \text { gluc,65.2 } \mathrm{kg}} \times[\mathrm{LBW} / 65.2]^{Z}$} \\
\hline $\mathrm{CL}_{\mathrm{E} \text { gluc, } 65.2 \mathrm{~kg}}$ & - & $0.222(6.3)$ & $0.221(0.198-0.251)$ \\
\hline$Z$ & - & $0.89(31)$ & $0.90(0.26-1.50)$ \\
\hline $\mathrm{CL}_{\mathrm{E} \text { sulph }}[\mathrm{L} / \mathrm{min}]$ & $0.097(3.3)$ & $0.096(3.4)$ & $0.096(0.090-0.102)$ \\
\hline $\mathrm{CL}_{\mathrm{E}}$ cys and mercap $[\mathrm{L} / \mathrm{min}]$ & $0.294(13.2)$ & $0.329(14.5)$ & $0.324(0.226-0.423)$ \\
\hline \multicolumn{4}{|l|}{ Inter-individual variability [\%] } \\
\hline$V_{\text {acetaminophen }}$ & $26.4(39.4)$ & $14.4(32.1)$ & $13.9(9.6-17.5)$ \\
\hline $\mathrm{CL}_{\text {gluc }}$ & $36.6(31.9)$ & $21.8(32.5)$ & $21.0(13.6-27.8)$ \\
\hline $\mathrm{CL}_{\text {sulph }}$ & $33.6(30)$ & $24.3(30.1)$ & $23.0(16.1-30.7)$ \\
\hline $\mathrm{CL}_{\mathrm{CYP} 2 \mathrm{E} 1}$ & $58.6(46.1)$ & $23.3(37.4)$ & $21.4(12.0-29.8)$ \\
\hline$V_{\text {glucuronide }}$ & $28.2(30)$ & $22.5(29.5)$ & $21.1(13.1-27.5)$ \\
\hline $\mathrm{CL}_{\mathrm{E} \text { gluc }}$ & $35.4(32)$ & $30.3(23.9)$ & $28.3(20.0-36.1)$ \\
\hline $\mathrm{CL}_{\mathrm{E} \text { cys and mercap }}$ & $52(34.1)$ & $34.9(33.4)$ & $34.0(21.8-49.2)$ \\
\hline \multicolumn{4}{|l|}{ Residual variability [\%] } \\
\hline Proportional error for acetaminophen & $17.2(26.9)$ & $17.1(27)$ & $16.7(13.4-21.6)$ \\
\hline
\end{tabular}


Table 2 continued

\begin{tabular}{llll}
\hline Parameter & Base model (RSE \%) & Final model (RSE \%) & $\begin{array}{l}\text { Bootstrap } \\
(95 \% \text { confidence interval) }\end{array}$ \\
\hline Proportional error for glucuronide & $19.6(27.5)$ & $19.7(27.9)$ & $19.3(14.7-25.0)$ \\
Proportional error for sulphate & $18.4(20.3)$ & $18.5(20.6)$ & $18.3(15.1-22.0)$ \\
Proportional error for cys and mercap & $24.8(9.2)$ & $25.0(8.7)$ & $24.9(22.7-27.0)$ \\
OFV [- 2LL] & -2937.3 & -3085.4 & $-3147.2(-3592.4$ to -2759.2$)$
\end{tabular}

$C L_{\text {gluc }}$ glucuronidation clearance, $C L_{\text {sulp }}$ sulphation clearance, $C L_{C Y P 2 E l}$ CYP2E1-mediated clearance, $C L_{E}$ gluc glucuronide elimination clearance, $C L_{E}$ sulph sulphate elimination clearance, $C L_{E}$ cys\&mercap cysteine \& mercapturate elimination clearance, $K \operatorname{tr}_{C Y P 2 E 1} \mathrm{CYP} 2 \mathrm{E} 1$ transit compartment rate constant, $K t r_{\text {gluc }}$ glucuronide transit compartment rate constant, $L B W$ lean body weight, $O F V$ objective function value, $Q$ intercompartmental clearance of acetaminophen sulphate between the central and peripheral compartment, $T B W$ total body weight, $V$ volume of distribution, -2LL -2 log likelihood(see also Fig. 1)

a The mean transit time was $158.7 \mathrm{~min}$

b The mean transit time was $175.4 \mathrm{~min}$

c The mean transit time was $10.5 \mathrm{~min}$

a Glucuronidation clearance

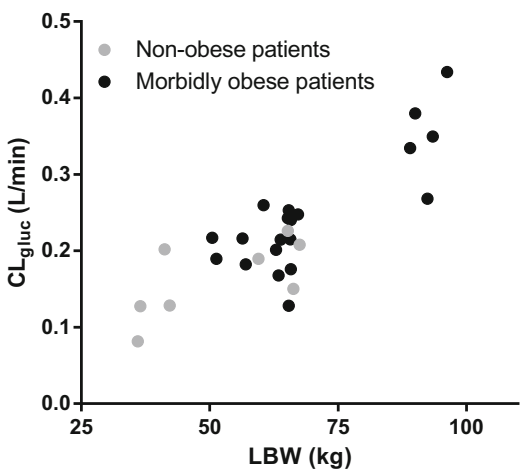

Fig. 3 Empirical Bayes estimates for morbidly obese patients $(n=20 ;$ black circles $)$ and non-obese patients $(n=8$; grey circles $)$ versus lean body weight (LBW), including a glucuronidation

identified as the strongest predictor for the volume of distribution of acetaminophen ( $V_{\text {acetaminophen }} ; P<0.001$, $\triangle \mathrm{OFV}-32$ ) and was selected over sex, which provided a $\triangle \mathrm{OFV}$ of only -16 . In addition, $\mathrm{CL}_{\text {gluc }}$ and $\mathrm{CL}_{\text {sulph }}$ proved to increase non-linearly with LBW $(P<0.001, \triangle \mathrm{OFV}-$ 31 ; and $P<0.001, \Delta \mathrm{OFV}-18$, respectively). The volume of distribution of acetaminophen glucuronide $\left(V_{\text {glucuronide }}\right)$ increased in a non-linear manner with TBW $(P<0.001$, $\triangle \mathrm{OFV}-12)$. The glucuronide elimination clearance $\left(\mathrm{CL}_{\mathrm{E} \text { gluc }}\right)$ increased with LBW $(P<0.001, \Delta \mathrm{OFV}-11)$. Lastly, LBW was a significant parameter for $\mathrm{CL}_{\mathrm{CYP} 2 \mathrm{E} 1}$ $(P<0.01, \Delta \mathrm{OFV}-8)$. Although the statistical significance for this last covariate was limited in the backward analysis $(P<0.05, \Delta \mathrm{OFV}+4.4)$, LBW on $\mathrm{CL}_{\mathrm{CYP} 2 \mathrm{E} 1}$ was kept in the model, since an improved fit in the goodness-of-fit plots of acetaminophen cysteine and mercapturate for the nonobese patients was shown.

Figure 3 shows the empirical Bayes estimates (EBEs) of the metabolic pathways of acetaminophen (i.e. $\mathrm{CL}_{\mathrm{gluc}}$,
C CYP2E1-mediated clearance

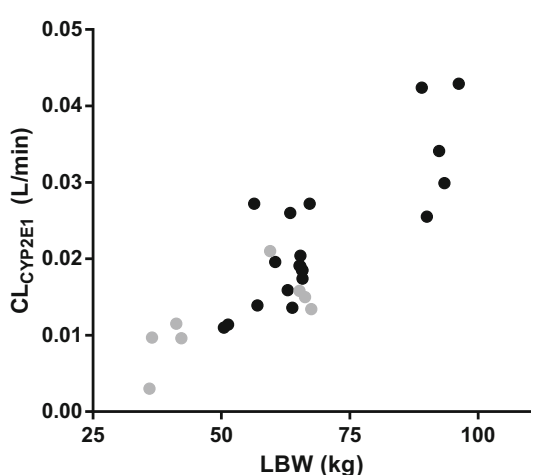

clearance $\left(\mathrm{CL}_{\text {gluc }}\right)$, b sulphation clearance $\left(\mathrm{CL}_{\text {sulph }}\right)$ and $\mathbf{c}$ cytochrome P450 2E1-mediated clearance $\left(\mathrm{CL}_{\mathrm{CYP} 2 \mathrm{E} 1}\right)$ [base pharmacokinetic model]

$\mathrm{CL}_{\text {sulph }}$ and $\mathrm{CL}_{\text {CYP2E1 }}$ ) versus LBW. After inclusion of the covariates in the model, the trends in the $\eta$ values of the parameters and the covariate disappeared, and no residual trends were observed (see Electronic Supplementary Material Fig. S1). This was also reflected by the reduction in IIV in the final model parameters in comparison with the IIV of the base model (Table 2).

The final model parameters are summarized in Table 2. Observed versus individual-predicted concentrations and observed versus population-predicted concentrations of acetaminophen, acetaminophen glucuronide, acetaminophen sulphate, and acetaminophen cysteine and mercapturate are shown in Fig. 4. The bootstrap analysis was successful in $99.6 \%$ of the runs and confirmed the model parameters (Table 2). Finally, VPCs for acetaminophen, acetaminophen glucuronide, acetaminophen sulphate, and acetaminophen cysteine and mercapturate for both morbidly obese and non-obese patients indicated good predictive performance, with good agreement between the 
Fig. 4 Observed versus individual-predicted and observed versus populationpredicted concentrations of acetaminophen (top row), acetaminophen glucuronide (second row), acetaminophen sulphate (third row) and acetaminophen cysteine and mercapturate (bottom row) in the final model for morbidly obese patients $(n=20$; black circles) and non-obese patients $(n=8$; grey circles). Ln lognormal

\section{Acetaminophen}

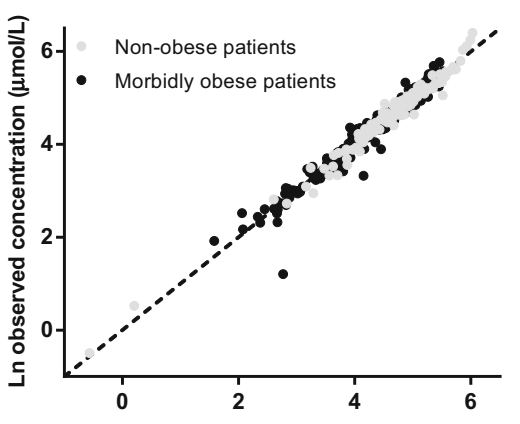

Ln individual predicted concentration ( $\mu \mathrm{mol} / \mathrm{L})$

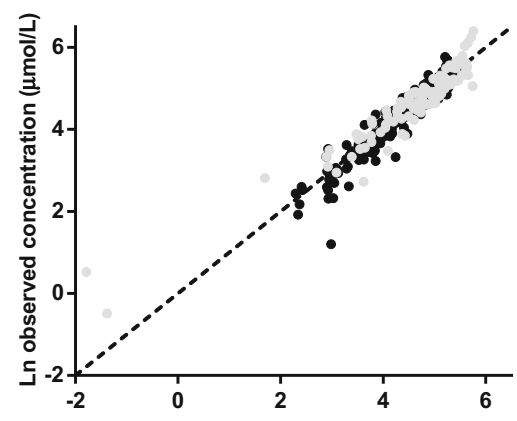

Ln population predicted concentration ( $\mu \mathrm{mol} / \mathrm{L}$ )

\section{Acetaminophen glucuronide}

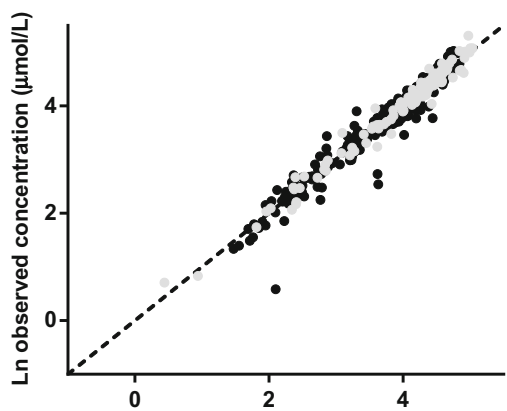

Ln individual predicted concentration $(\mu \mathrm{mol} / \mathrm{L})$

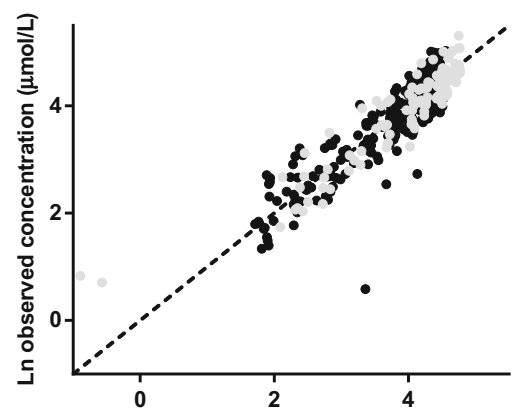

Ln population predicted concentration ( $\mu \mathrm{mol} / \mathrm{L}$ )

\section{Acetaminophen sulphate}
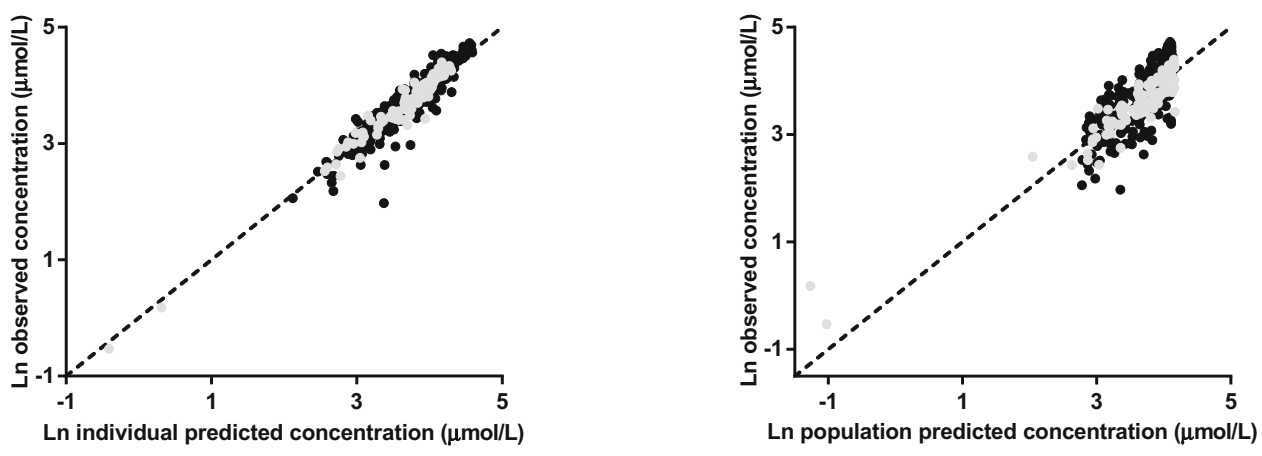

Acetaminophen cysteine \& mercapturate
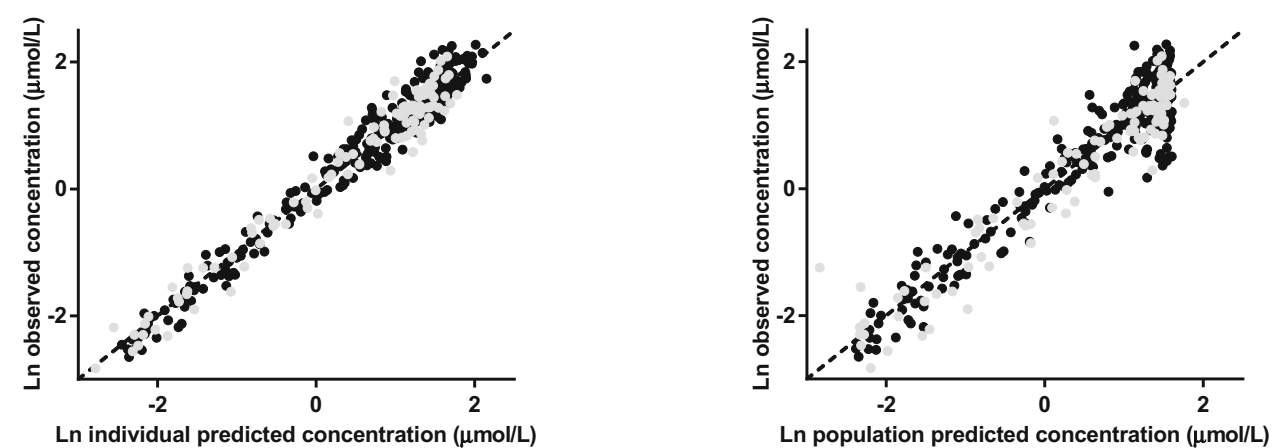
Fig. 5 Visual predictive checks of the final model for acetaminophen (top row), acetaminophen glucuronide (second row), acetaminophen sulphate (third row) and acetaminophen cysteine and mercapturate [cys and mercap] (bottom row) in morbidly obese patients (left graphs) and nonobese patients (right graphs).

The observed concentrations are shown as blue circles, and the medians (and 2.5th and 97.5th percentiles) of the observed data are shown as solid red lines (and lower and upper dashed red lines, respectively). The pink shaded areas represent the $95 \%$ confidence intervals for the medians of the simulated concentrations $(n=1000)$, based on the original data set, and the lower and upper blue shaded areas represent the $95 \%$ confidence intervals of the 2.5th and 97.5 th percentiles, respectively
Acetaminophen morbidly obese patients

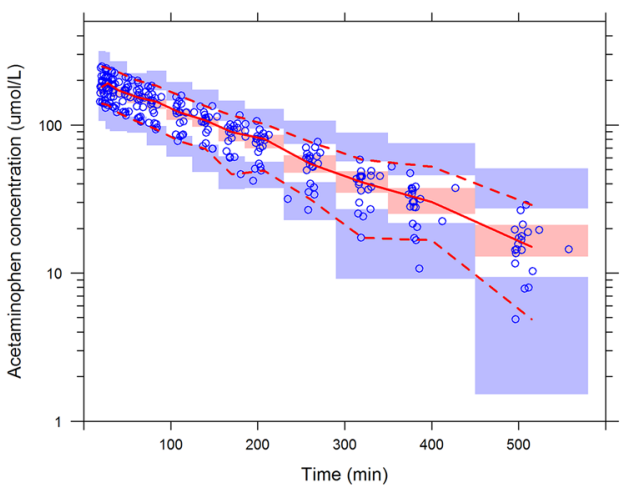

Acetaminophen glucuronide morbidly obese patients

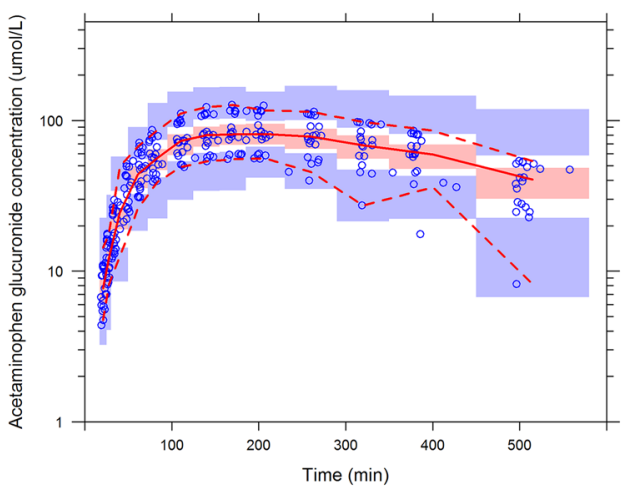

Acetaminophen sulphate morbidly obese patients

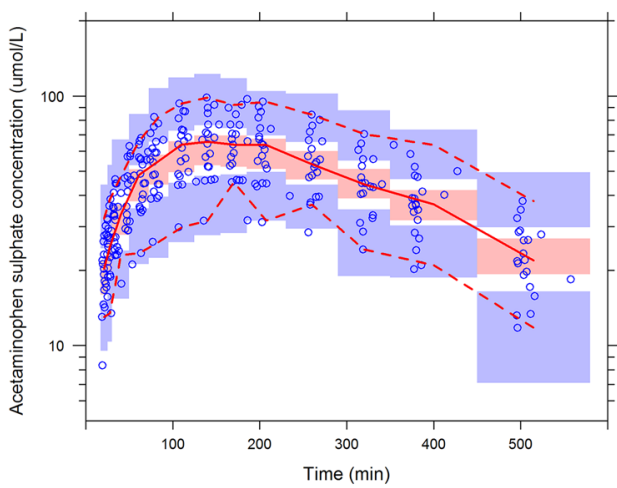

Acetaminophen cys \& mercap morbidly obese patients

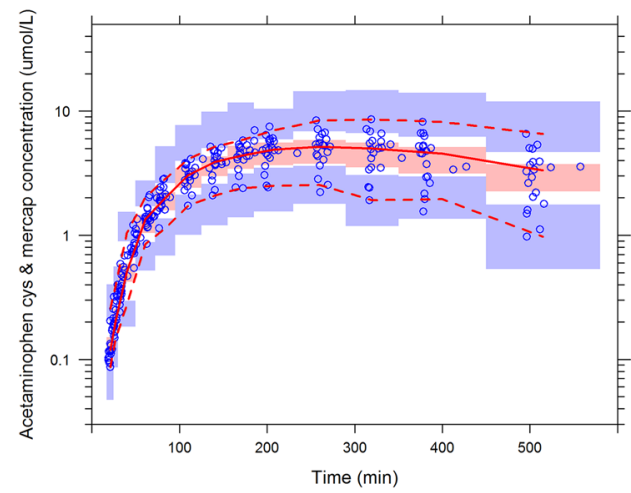

Acetaminophen non-obese patients

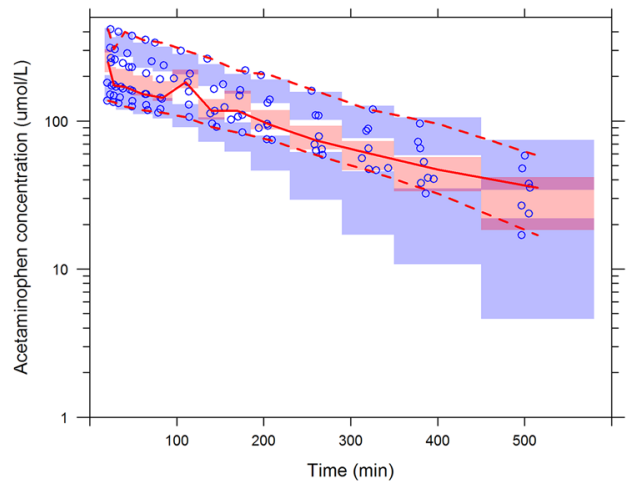

Acetaminophen glucuronide non-obese patients

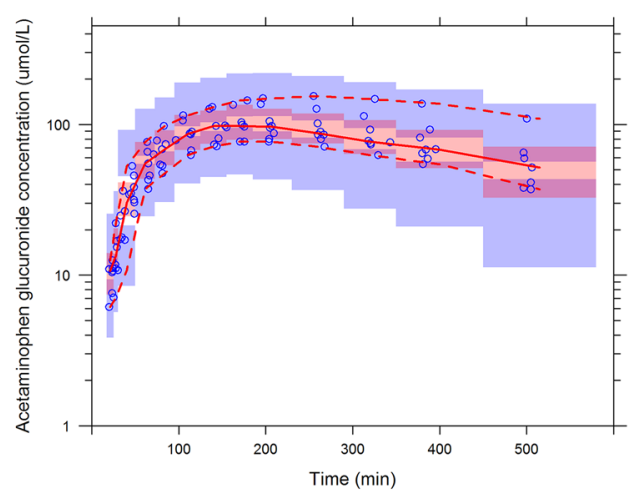

Acetaminophen sulphate non-obese patients

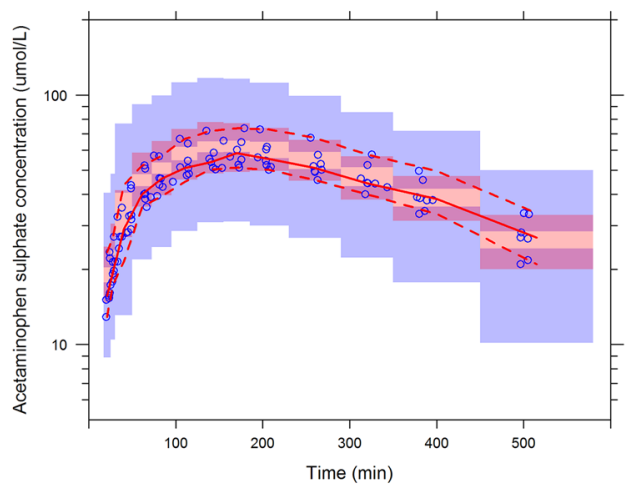

Acetaminophen cys \& mercap non-obese patients

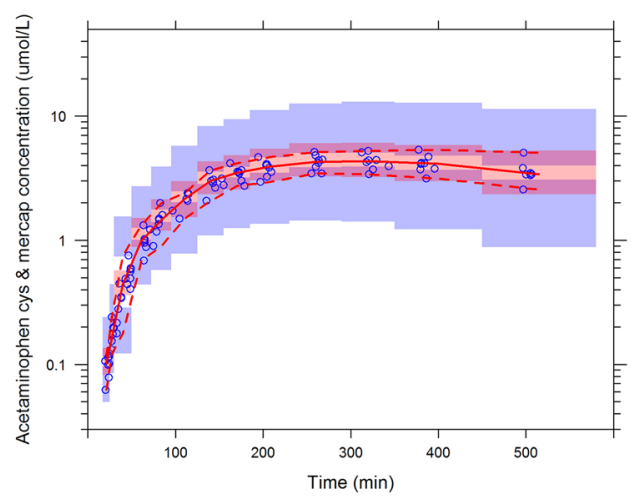



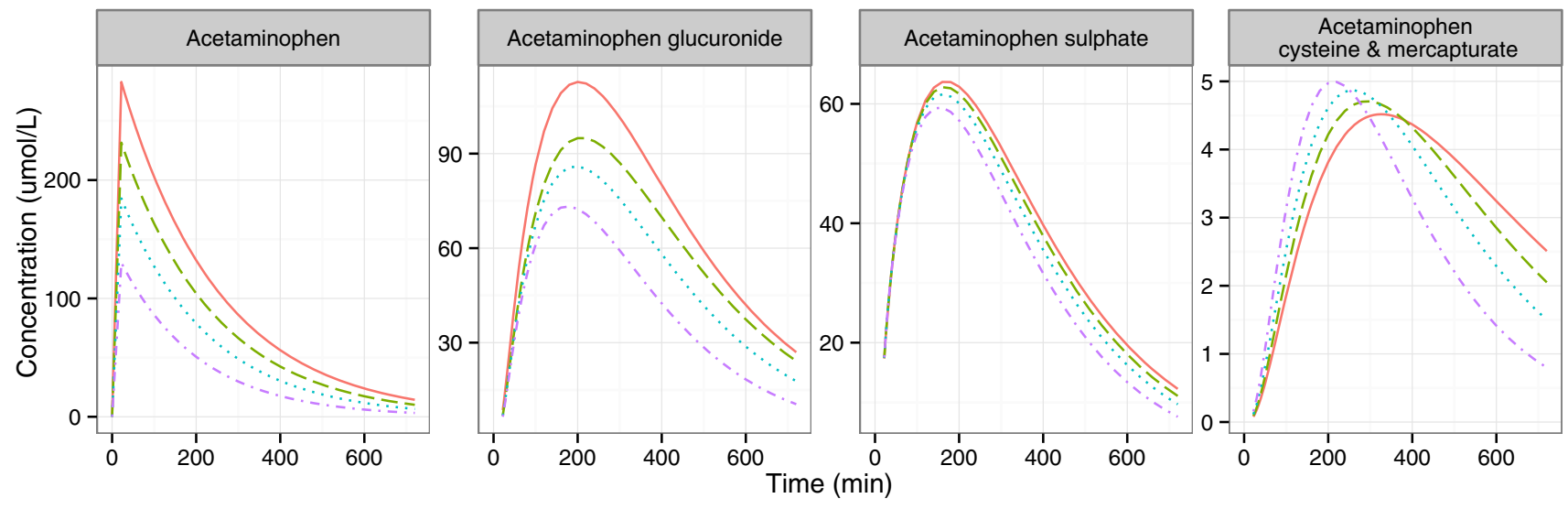

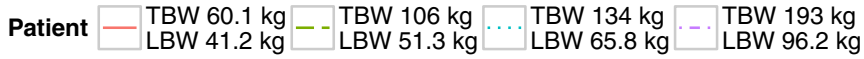

Fig. 6 Population-predicted acetaminophen concentrations (first graph), acetaminophen glucuronide concentrations (second graph), acetaminophen sulphate concentrations (third graph) and acetaminophen cysteine and mercapturate concentrations (fourth graph) over time in one non-obese patient (with total body weight [TBW] of

observed data and the model-simulated confidence intervals for the medians and the 2.5th and 97.5th percentiles (Fig. 5).

\subsection{Simulations}

Figure 6 shows population-predicted acetaminophen, acetaminophen glucuronide, acetaminophen sulphate, and acetaminophen cysteine and mercapturate concentrations after a $2 \mathrm{~g}$ intravenous dose of acetaminophen administered over $20 \mathrm{~min}$ in four representative patients (with TBWs of $60.1,106,134$ and $193 \mathrm{~kg}$, and LBWs of 41.2, $51.3,65.8$ and $96.2 \mathrm{~kg}$, respectively). The maximum concentration $\left(C_{\max }\right)$ value for acetaminophen and $C_{\max }$ and $t_{\text {max }}$ values for acetaminophen glucuronide were lower in patients with greater body weight (Fig. 6a, b). For acetaminophen sulphate, the $C_{\max }$ and $t_{\max }$ values were slightly lower in heavier patients (Fig. 6c). For acetaminophen cysteine and mercapturate, the $C_{\max }$ value was higher and the $t_{\max }$ value was lower in patients with greater body weight (Fig. 6d).

\subsection{4-h Liver Function Markers}

Morbidly obese patients had significantly higher AST, ALT, bilirubin and PT values at $24 \mathrm{~h}$ after the $2 \mathrm{~g}$ intravenous acetaminophen infusion than before acetaminophen administration $(P<0.05$, Table 3$)$. Two morbidly obese patients had more than three times increased AST levels (i.e. 102 and $140 \mathrm{U} / \mathrm{L}$ ), and one morbidly obese patient had more than three times increased ALT levels (i.e. $128 \mathrm{U} / \mathrm{L}$ ). Non-obese patients did not show significantly elevated
$60.1 \mathrm{~kg}$ and lean body weight [LBW] of $41.2 \mathrm{~kg}$ ) and in three morbidly obese patients (with TBWs of 106, 134 and $193 \mathrm{~kg}$; and with LBWs of 51.3, 65.8 and $96.2 \mathrm{~kg}$, respectively) after $2 \mathrm{~g}$ of intravenous acetaminophen

AST or ALT levels at $24 \mathrm{~h}$ in comparison with the levels before acetaminophen administration, with significant increases only in bilirubin and PT values $(P<0.05$, Table 3).

\section{Discussion}

In view of the known induced CYP2E1 metabolism in obese individuals, this study aimed to determine the pharmacokinetics of acetaminophen and all of its metabolites (glucuronide, sulphate, cysteine and mercapturate) in morbidly obese versus non-obese patients. The results of this study show that the lower exposure to acetaminophen in morbidly obese patients resulting from an increased total clearance of acetaminophen, as has been reported before [13], can be explained by increases in all three metabolic pathways (i.e. glucuronidation, sulphation and CYP2E1-mediated clearance).

This study is the first to report an increased CYP2E1mediated clearance of acetaminophen in morbidly obese patients. Previously, this pathway has been investigated only in obese rats, where clearance to the cysteine and mercapturate metabolites was increased by $56 \%$ after administration of a sub-toxic dose of acetaminophen [22]. The increased CYP2E1-mediated clearance in the obese is consistent with investigations on other CYP2E1-mediated drugs, i.e. chlorzoxazone, enflurane and sevoflurane [15, $18,33,34]$. NAFLD may be the underlying cause of increased CYP2E1 expression in obese patients [24]. NAFLD refers to a large spectrum of conditions ranging from fatty liver to non-alcoholic steatohepatitis (NASH) 
Table 3 Liver function markers before $(T=0)$ and $24 \mathrm{~h}$ after $(T=24)$ the $2 \mathrm{~g}$ intravenous acetaminophen dose and subsequent standard-ofcare doses of acetaminophen in morbidly obese and non-obese patients

\begin{tabular}{|c|c|c|c|c|c|c|}
\hline \multirow[t]{2}{*}{ Liver function markers } & \multicolumn{3}{|c|}{ Morbidly obese patients, $n=20$} & \multicolumn{3}{|c|}{ Non-obese patients, $n=8$} \\
\hline & $T=0, n=20$ & $T=24, n=18^{\mathrm{a}}$ & $P$ value & $T=0, n=8$ & $T=24, n=8^{b}$ & $P$ value \\
\hline $\begin{array}{l}\text { AST }[\mathrm{U} / \mathrm{L}] \\
R R: \hat{\jmath}<35 \mathrm{U} / \mathrm{L}, \stackrel{+}{+}<31 \mathrm{U} / \mathrm{L}\end{array}$ & $26.0(14.0-40.0)$ & $34.5(20.0-140.0)$ & 0.017 & $22.0(18.0-28.0)$ & $22.5(17.0-52.0)$ & $>0.05$ \\
\hline $\begin{array}{l}\mathrm{ALT}[\mathrm{U} / \mathrm{L}] \\
R R: \text { o }<45 \mathrm{U} / \mathrm{L}, \text { }+<34 \mathrm{U} / \mathrm{L}\end{array}$ & $30.5(12.0-58.0)$ & $38.5(14.0-128.0)$ & 0.022 & $19.5(7.0-33.0)$ & $18.0(7.0-28.0)$ & $>0.05$ \\
\hline $\begin{array}{l}\gamma \text {-GT }[\mathrm{U} / \mathrm{L}] \\
R R: \hat{\sigma}<55 \mathrm{U} / \mathrm{L}, \text { }+<38 \mathrm{U} / \mathrm{L}\end{array}$ & $29.5(13.0-99.0)$ & $29.0(14.0-82.0)$ & $>0.05$ & $12.5(8.0-27.0)$ & $11.0(4.0-28.0)$ & 0.048 \\
\hline $\begin{array}{l}\text { Bilirubin }[\mu \mathrm{mol} / \mathrm{L}] \\
R R: 1-17 \mu \mathrm{mol} / \mathrm{L}\end{array}$ & $6.0(3.0-17.0)$ & $7.0(4.0-20.0)$ & 0.014 & $8.0(4.0-18.0)$ & $12.0(6.0-29.0)$ & 0.012 \\
\hline $\begin{array}{l}\mathrm{PT}[\mathrm{s}] \\
R R: 12.0-15.5 \mathrm{~s}\end{array}$ & $12.8(12.3-13.9), n=15$ & $13.3(13.0-13.7), n=13$ & 0.004 & $12.9(12.4-13.4)$ & $14.1(13.0-16.2)$ & 0.012 \\
\hline
\end{tabular}

Values are expressed as median (range)

o male, + female, $\gamma$-GT $\gamma$-glutamyltranspeptidase, ALT alanine aminotransferase, AST aspartate aminotransferase, $P T$ prothrombin time, $R R$ reference range

a The total administered dose over $24 \mathrm{~h}$ was $2 \mathrm{~g}$ of intravenous acetaminophen plus median standard-of-care doses of acetaminophen $3 \mathrm{~g}(0-3 \mathrm{~g})$

b The total administered dose over $24 \mathrm{~h}$ was $2 \mathrm{~g}$ of intravenous acetaminophen plus median standard-of-care doses of acetaminophen $2 \mathrm{~g}(0-4 \mathrm{~g})$

and cirrhosis [11, 24]. Different studies have shown a causal relationship between CYP2E1-mediated clearance $[18,19]$ or protein expression and steatosis or NASH measured with a needle biopsy of the liver [17-19]. In addition, weight loss has been associated with a significant decrease in CYP2E1-mediated clearance and CYP2E1 protein content after bariatric surgery [17, 33], with the decrease in CYP2E1-mediated clearance protein content being associated with a significant reduction in lipid peroxidation levels [17]. Another cause of the increased expression of CYP2E1 that has been postulated is insulin resistance, which is often observed in obese individuals [24].

Besides increased CYP2E1-mediated clearance, our study showed an increase in glucuronidation clearance of acetaminophen with increasing LBW. Higher absolute acetaminophen clearance values and 2-fold higher acetaminophen glucuronide urine concentrations have also been reported in obese adolescents with NAFLD in comparison with non-obese adolescents without NAFLD [15, 16]. In addition, for other UGT-mediated drugs (i.e. garenoxacin, oxazepam and lorazepam), increased clearance has been demonstrated in obese subjects in comparison with non-obese subjects $[14,15]$. However, Hardwick et al. [23] reported no alteration in UGT activity of acetaminophen in human liver tissue samples diagnosed with NAFLD, but this UGT activity was reported per milligram of protein and not per liver. In addition, no alteration in the glucuronidation capacity of morphine was reported by Ferslew et al. [35], since morphine pharmacokinetics did not differ between obese patients with NASH and nonobese healthy subjects. The differences in the findings on morphine and acetaminophen may, in our opinion, be explained by the fact that morphine-in contrast to acetaminophen-is a relatively high-extraction-ratio drug of which the clearance is dependent on hepatic blood flow [36]. The fact that in that study, elevated morphine glucuronide concentrations were found in obese NASH patients, were (according to the authors) explained by alterations in hepatic membrane transporters, i.e. multidrug resistance-associated protein (MRP)-3, instead of increased glucuronidation clearance of morphine [35]. Recently, Canet et al. [37] reported increased acetaminophen glucuronide concentrations in paediatric NASH patients. In their opinion, these results could be explained by hepatic membrane transporter dysregulation of MRP2 and MRP3. Their conclusions were, however, based on three NASH patients and on glucuronide concentrations only, without modelling of the data in a population model. Given the results of the current study, we think it is justified to conclude that glucuronidation capacity is increased in morbidly obese patients.

In this report, we show an increase in sulphation of acetaminophen with weight. Previously, changes in the sulphate conjugation pathway were examined only in obese rodent models, showing contradictory results [20-22]. In human NAFLD liver microsomes, an increase in sulfotransferase activity was reported in steatosis liver samples, but there was decreased activity in NASH liver samples (per milligram of protein) [23]. Moreover, in paediatric 
NASH patients, a non-significant decrease in acetaminophen sulphate concentrations was reported [37]. In our study, we found a correlation between the patients' triglyceride levels and $\mathrm{CL}_{\text {sulph }}(\triangle \mathrm{OFV}-17)$, but since weight and triglycerides were correlated, LBW was included in the model. Because of these results, we think that our finding of an increase in sulphation with weight could be caused by steatosis of the liver in morbidly obese patients.

The dose simulations based on the final model in Fig. 6 illustrate the clinical relevance of the findings of this study. The acetaminophen $C_{\max }$ values were substantially lower in patients with greater body weight, because of the greater volume of distribution of acetaminophen with increasing LBW (Fig. 6a). The acetaminophen half-life $\left(t_{1 / 2}\right)$ was equal for morbidly obese and non-obese patients (Fig. 6a) and can be explained by an increase in both the volume of distribution and clearance of acetaminophen. For acetaminophen glucuronide, $t_{\max }$ decreased with increasing weight (Fig. 6b), because of greater glucuronidation clearance. The $C_{\max }$ of acetaminophen glucuronide was lower with increasing weight (Fig. 6b) and could be explained by the greater glucuronide elimination clearance with LBW and by the increases in volume of distribution of acetaminophen and glucuronide with increasing weight. Despite greater sulphation clearance, the concentrationtime profile values of acetaminophen sulphate were slightly lower in morbidly obese patients than in non-obese patients (Fig. 6c), which could be explained by the greater $V_{\text {ac- }}$ etaminophen. For acetaminophen cysteine and mercapturate, the $t_{\max }$ was shorter in morbidly obese patients, because of the higher CYP2E1 transit compartment rate constant of acetaminophen, leading to a decrease in the mean transit time. Despite the increase in CYP2E1-mediated clearance, the $C_{\max }$ values were only slightly higher in morbidly obese patients than in non-obese patients, because of the greater volume of distribution of acetaminophen with LBW.

Although the absolute cysteine and mercapturate AUC values were not substantially higher in morbidly obese patients (Fig. 6), we emphasize that one should be reluctant to give a higher acetaminophen dose to obese individuals, as it is not known whether earlier and greater formation of CYP2E1-mediated metabolites may contribute to acetaminophen hepatotoxicity. Moreover, the $\mathrm{AUC}_{0-8 \mathrm{~h}}$ ratio of the cysteine metabolite was significantly increased in morbidly obese patients (Fig. 2). Increasing the standard dose from 1 to $2 \mathrm{~g}$ in morbidly obese patients is therefore not recommended, despite our finding that acetaminophen concentrations are lower in morbidly obese patients than in non-obese patients. This advice is further substantiated by the significantly increased AST, ALT, bilirubin and PT values at $24 \mathrm{~h}$ after the initial $2 \mathrm{~g}$ administration (with total median doses over $24 \mathrm{~h}$ of $4 \mathrm{~g}$ [range 2-6 g] in non-obese patients and $5 \mathrm{~g}[2-5 \mathrm{~g}]$ in morbidly obese patients, $P>0.05)$ in comparison with the levels before acetaminophen administration, although these values were still close to the reference ranges (Table 3). Two morbidly obese patients had $>3$ times increased levels of AST, and one patient had a $>3$ times increased level of ALT in comparison with the reference values (shown in Table 3). While the exact values of these increases-which may potentially relate to the bariatric surgical procedure itselfare unknown, the difference in comparison with non-obese patients is clear (Table 3 ).

There were some limitations of this study. First, the surgery time in the non-obese patients was significantly longer in comparison with the obese patients, which may potentially have influenced the pharmacokinetics of acetaminophen. Second, the study can be considered as a small study $(n=20+8)$, although for pharmacokinetic studies, a smaller number of patients is typically accepted. Third, whether the patients suffered from NAFLD could not be determined in this study, since there was no possibility to take a liver biopsy from these patients. To gain an impression as to whether the morbidly obese patients were metabolically different from the non-obese patients, samples for insulin resistance, lipid levels and CRP levels (Table 1) were collected.

\section{Conclusion}

Obesity leads to lower acetaminophen concentrations, with earlier and higher peak concentrations of the cysteine and mercapturate metabolites. While a higher dose may be anticipated to achieve adequate acetaminophen concentrations, the increased CYP2E1-mediated pathway may preclude this dose adjustment.

Acknowledgments The authors thank the bariatric nurses Brigitte Bliemer and Silvia Samson for their help in recruiting patients; and the anesthesiologists, residents, ward nurses and recovery room nurses for their help with the clinical trial. The authors also thank Tamara van Steeg from LAP\&P Consultants for her technical support with NONMEM. Diana Wilkins, Amber King and Sarah Cook from the Center for Human Toxicology, University of Utah, are acknowledged for measuring the plasma samples. The authors thank Darrell R. Abernethy for his valuable input into the research protocol and for critically reading the manuscript.

\section{Compliance with Ethical Standards}

All procedures performed in studies involving human participants were in accordance with the ethical standards of the institutional and/ or national research committee and with the 1964 Helsinki Declaration and its later amendments or comparable ethical standards. Informed consent was obtained from all individual participants included in the study. Anne van Rongen, Pyry A. J. Välitalo, Mariska Y. M. Peeters, Djamila Boerma, Fokko W. Huisman, 
Bert van Ramshorst, Eric P. A. van Dongen, Johannes N. van den Anker and Catherijne A. J. Knibbe declare that they have no potential conflicts of interests. No sources of funding were used in the preparation of this manuscript.

Open Access This article is distributed under the terms of the Creative Commons Attribution-NonCommercial 4.0 International License (http://creativecommons.org/licenses/by-nc/4.0/), which permits any noncommercial use, distribution, and reproduction in any medium, provided you give appropriate credit to the original author(s) and the source, provide a link to the Creative Commons license, and indicate if changes were made.

\section{References}

1. Ng M, Fleming T, Robinson M, Thomson B, Graetz N, Margono $\mathrm{C}$, et al. Global, regional, and national prevalence of overweight and obesity in children and adults during 1980-2013: a systematic analysis for the Global Burden of Disease Study 2013. Lancet. 2014;384(9945):766-81.

2. Saurabh S, Smith JK, Pedersen M, Jose P, Nau P, Samuel I. Scheduled intravenous acetaminophen reduces postoperative narcotic analgesic demand and requirement after laparoscopic Roux-en-Y gastric bypass. Surg Obes Relat Dis. 2015;11(2):424-30.

3. Prescott LF. Kinetics and metabolism of paracetamol and phenacetin. Br J Clin Pharmacol. 1980;10(Suppl 2)(221):291S-8S.

4. Clements JA, Critchley JA, Prescott LF. The role of sulphate conjugation in the metabolism and disposition of oral and intravenous paracetamol in man. $\mathrm{Br} \mathrm{J}$ Clin Pharmacol. 1984;18(4):481-5.

5. Critchley JA, Nimmo GR, Gregson CA, Woolhouse NM, Prescott LF. Inter-subject and ethnic differences in paracetamol metabolism. Br J Clin Pharmacol. 1986;22(6):649-57.

6. Rumack BH. Acetaminophen hepatotoxicity: the first 35 years. J Toxicol Clin Toxicol. 2002;40(208):3-20.

7. Park JM, Lin YS, Calamia JC, Thummel KE, Slattery JT, Kalhorn TF, et al. Transiently altered acetaminophen metabolism after liver transplantation. Clin Pharmacol Ther. 2003;73(209):545-53.

8. Manyike PT, Kharasch ED, Kalhorn TF, Slattery JT. Contribution of CYP2E1 and CYP3A to acetaminophen reactive metabolite formation. Clin Pharmacol Ther. 2000;67(206):275-82.

9. Chun LJ, Tong MJ, Busuttil RW, Hiatt JR. Acetaminophen hepatotoxicity and acute liver failure. J Clin Gastroenterol. 2009;43(207):342-9.

10. Forrest JA, Clements JA, Prescott LF. Clinical pharmacokinetics of paracetamol. Clin Pharmacokinet. 1982;7(2):93-107.

11. Michaut A, Moreau C, Robin MA, Fromenty B. Acetaminopheninduced liver injury in obesity and nonalcoholic fatty liver disease. Liver Int. 2014;34(7):e171-9.

12. Larson AM, Polson J, Fontana RJ, Davern TJ, Lalani E, Hynan LS, et al. Acetaminophen-induced acute liver failure: results of a United States multicenter, prospective study. Hepatology. 2005;42(6):1364-72.

13. Abernethy DR, Divoll M, Greenblatt DJ, Ameer B. Obesity, sex, and acetaminophen disposition. Clin Pharmacol Ther. 1982;31(203):783-90.

14. Abernethy DR, Greenblatt DJ, Divoll M, Shader RI. Enhanced glucuronide conjugation of drugs in obesity: studies of lorazepam, oxazepam, and acetaminophen. J Lab Clin Med. 1983;101(213):873-80.
15. Brill MJE, Diepstraten J, van Rongen A, van Kralingen S, van den Anker JN, Knibbe CAJ. Impact of obesity on drug metabolism and elimination in adults and children. Clin Pharmacokinet. 2012;51(223):277-304.

16. Barshop NJ, Capparelli EV, Sirlin CB, Schwimmer JB, Lavine JE. Acetaminophen pharmacokinetics in children with nonalcoholic fatty liver disease. J Pediatr Gastroenterol Nutr. 2011;52(175):198-202.

17. Bell LN, Temm CJ, Saxena R, Vuppalanchi R, Schauer P, Rabinovitz M, et al. Bariatric surgery-induced weight loss reduces hepatic lipid peroxidation levels and affects hepatic cytochrome P-450 protein content. Ann Surg. 2010;251(243):1041-8.

18. Chtioui H, Semela D, Ledermann M, Zimmermann A, Dufour JF. Expression and activity of the cytochrome P450 2E1 in patients with nonalcoholic steatosis and steatohepatitis. Liver Int. 2007;27(6):764-71.

19. Varela NM, Quinones LA, Orellana M, Poniachik J, Csendes A, Smok G, et al. Study of cytochrome P450 2E1 and its allele variants in liver injury of nondiabetic, nonalcoholic steatohepatitis obese women. Biol Res. 2008;41(1):81-92.

20. Chaudhary IP, Tuntaterdtum S, McNamara PJ, Robertson LW, Blouin RA. Effect of genetic obesity and phenobarbital treatment on the hepatic conjugation pathways. J Pharmacol Exp Ther. 1993;265(216): 1333-8.

21. Corcoran GB, Wong BK, Shum L, Galinsky RE. Acetaminophen sulfation deficit in obese rats overfed an energy-dense cafeteria diet. Endocr Res. 1987;13(214):101-21.

22. Wong BK, Ernest U SW, Corcoran GB. An overfed rat model that reproduces acetaminophen disposition in obese humans. Drug Metab Dispos. 1986;14(238):674-9.

23. Hardwick RN, Ferreira DW, More VR, Lake AD, Lu Z, Manautou JE, et al. Altered UDP-glucuronosyltransferase and sulfotransferase expression and function during progressive stages of human nonalcoholic fatty liver disease. Drug Metab Dispos. 2013;41(3):554-61.

24. Aubert J, Begriche K, Knockaert L, Robin MA, Fromenty B. Increased expression of cytochrome P450 2E1 in nonalcoholic fatty liver disease: mechanisms and pathophysiological role. Clin Res Hepatol Gastroenterol. 2011;35(242):630-7.

25. Cook SF, King AD, van den Anker JN, Wilkins DG. Simultaneous quantification of acetaminophen and five acetaminophen metabolites in human plasma and urine by high-performance liquid chromatography-electrospray ionization-tandem mass spectrometry: method validation and application to a neonatal pharmacokinetic study. J Chromatogr B. 2015;1007:30-42.

26. R Development Core Team. R: a language and environment for statistical computing. Vienna: $\mathrm{R}$ Foundation for Statistical Computing; 2008.

27. Beal S, Sheiner LB, Boeckmann A, Bauer RJ. NONMEM user's guides (1989-2009). Ellicott City: Icon Development Solutions; 2009.

28. Keizer RJ, Karlsson MO, Hooker A. Modeling and simulation workbench for NONMEM: tutorial on Pirana, PsN, and Xpose. CPT Pharmacometrics Syst Pharmacol. 2013;2(43):e50.

29. Beal SL. Ways to fit a PK model with some data below the quantification limit. $\mathrm{J}$ Pharmacokinet Pharmacodyn. 2001;28(39):481-504.

30. Byon W, Fletcher CV, Brundage RC. Impact of censoring data below an arbitrary quantification limit on structural model misspecification. J Pharmacokinet Pharmacodyn. 2008;35(40):101-16.

31. Owens KH, Murphy PG, Medlicott NJ, Kennedy J, Zacharias M, Curran N, et al. Population pharmacokinetics of intravenous acetaminophen and its metabolites in major surgical patients. J Pharmacokinet Pharmacodyn. 2014;41(3):211-21. 
32. Janmahasatian S, Duffull SB, Ash S, Ward LC, Byrne NM, Green B. Quantification of lean bodyweight. Clin Pharmacokinet. 2005;44(31):1051-65.

33. Emery MG, Fisher JM, Chien JY, Kharasch ED, Dellinger EP, Kowdley KV, et al. CYP2E1 activity before and after weight loss in morbidly obese subjects with nonalcoholic fatty liver disease. Hepatology. 2003;38(174):428-35.

34. O'Shea D, Davis SN, Kim RB, Wilkinson GR. Effect of fasting and obesity in humans on the 6-hydroxylation of chlorzoxazone: a putative probe of CYP2E1 activity. Clin Pharmacol Ther. 1994;56(222):359-67.
35. Ferslew BC, Johnston CK, Tsakalozou E, Bridges AS, Paine MF, Jia W, et al. Altered morphine glucuronide and bile acid disposition in patients with nonalcoholic steatohepatitis. Clin Pharmacol Ther. 2015;97(4):419-27.

36. Lloret Linares C, Decleves X, Oppert JM, Basdevant A, Clement $\mathrm{K}$, Bardin C, et al. Pharmacology of morphine in obese patients: clinical implications. Clin Pharmacokinet. 2009;48(10):635-51.

37. Canet MJ, Merrell MD, Hardwick RN, Bataille AM, Campion SN, Ferreira DW, et al. Altered regulation of hepatic efflux transporters disrupts acetaminophen disposition in pediatric nonalcoholic steatohepatitis. Drug Metab Dispos. 2015;43(6):829-35. 